\title{
ENSINO DE CIÊNCIAS PAUTADO NAS RELAÇÕES CULTURAIS COM O AMBIENTE PARA A EDUCAÇÃO DO CAMPO
}

\author{
LINED SCIENCE TEACHING IN CULTURAL RELATIONS WITH THE \\ ENVIRONMENT FOR THE FIELD OF EDUCATION
}

Elaine Cristine do Amarante Matos ${ }^{1}$

\begin{abstract}
RESUMO: Por atender comunidades com características culturais diferentes das populações urbanas, o ensino em escolas do campo requer adaptações ao currículo formal, de modo a adequar-se às necessidades da comunidade local. Dessa forma, propõe-se que o ensino de Ciências na educação do campo contemple a inserção e discussão de outros saberes acerca dos conteúdos de ciências lecionados em sala, pois esses conteúdos devem ser ressignificados e percebidos de acordo com o ambiente educacional específico. Como embasamento a essa proposta, utilizam-se as contribuições dos Estudos Culturais para a educação e posicionamentos de autores multiculturalistas e pluralistas sobre o ensino de Ciências. Assim, sugerimos a inserção dos conhecimentos etnobiológicos nos currículos de Ciências em escolas do campo, buscando a ampliação dos saberes em relação à Biologia, como também a valorização do conhecimento cultural da comunidade. Palavras-chave: Educação do campo. Estudos culturais. Pluralismo epistemológico. Etnobiologia. Cultura.
\end{abstract}

\begin{abstract}
For meeting communities with different cultural characteristics of urban populations, teaching in the rural schools requires adjustments to the formal curriculum in order to suit the needs of the local community. Thus, it is proposed that science teaching in rural education contemplate the inclusion and discussion of other knowledge about the science content taught in class, as these contents should be reevaluated and perceived according to the specific educational environment. To support such a proposal, are used contributions of Cultural Studies for education and placements of multicultural and pluralistic authors on science teaching. Thus, we suggest the inclusion of ethnobiological knowledge in the science curriculum of rural schools, seeking the expansion of knowledge regarding the biology, as well as enhancing the cultural knowledge of the community.
\end{abstract}

Keywords: Rural education. Cultural Studies. Epistemological pluralismo. Etnobiology. Culture. 


\section{Introdução}

A rede pública escolar que atende comunidades não urbanizadas configura quase metade de toda a rede do país. Segundo dados do governo federal, existem 83 mil escolas rurais no Brasil, o que representa $42 \%$ do total de escolas no país (AGÊNCIA BRASIL, 2010). Essas comunidades são caracterizadas por uma população de agricultores, pessoas que vivem em áreas rurais para as quais a agricultura é o principal meio de sustento (PETTY et alli, 1981; SOARES et alli, 2006), e também por indivíduos que vivem em espaços de floresta, pecuária, minas, pesqueiros, caiçaras, ribeirinhos e extrativistas, conforme o relatório das Diretrizes Operacionais para a Educação Básica nas escolas do campo (BRASIL, 2002).

Os grupos sociais não urbanizados (rurais, pesqueiros, extrativistas, indígenas, quilombolas, entre outros) possuem temporalidade, práticas laborais e culturas diferentes do ambiente urbano, contexto em que está pautado o currículo de Ciências oficial no país (SILVA et alli, 2006). Diante dessa diversidade, é necessária a formulação de medidas para promover uma educação de qualidade para comunidades com características tão diversas em um universo tão representativo.

Dentre as várias iniciativas para contemplar as necessidades de tais comunidades, nasceu o movimento "Por uma educação do campo", formado por movimentos sociais de pesquisadores de diversas áreas, como educação e sociologia, que buscavam construir uma política educacional e uma prática pedagógica que contemplassem as necessidades reais das comunidades não urbanizadas. É importante ressaltar o uso do termo "educação do campo" ao invés de "rural". A educação do campo difere da educação rural no sentido de que a rural trata da educação do meio não urbano, e a educação "do campo" define a educação de uma sociedade com identidade cultural própria e práticas sociais e trabalhistas características de um meio que não é o urbano (SILVA et alli, 2006).

Apesar de abranger parcela considerável da população, é possível observar que as políticas públicas específicas para a educação do campo que estão vigentes ainda são superficiais e, portanto, incipientes. Nesse contexto, a adequação dos saberes é recomendada (CALDART, 2004) como medida paliativa à situação, atenuando e adiando o problema.

Dentre as perspectivas de possíveis abordagens para adequação de saberes ao ensino de ciências no campo, destacam-se as práticas pedagógicas pautadas nas relações culturais com o ambiente. Para tanto, sugiro inicialmente a contribuição dos Estudos Culturais para as práticas pedagógicas na educação do campo, que propõem serem discutidas em sala de aula questões acerca da abordagem das diversas identidades culturais e também as diferenças, no espaço escolar e no currículo (PARAísO, 2004).

Ao trazer especificamente para os conteúdos científicos, a influência cultural também pode ser discutida em relação à forma como o conhecimento científico é produzido, aos conteúdos que compõem o currículo formal da disciplina Ciências e à maneira como estes são ensinados em sala de aula, pois os conteúdos de Ciências selecionados pela escola devem ser ressignificados e percebidos de acordo com um ambiente educacional específico (BIZZO, 2009).

Somado a isso, as comunidades camponesas tem formas de saber que podem contribuir para o enriquecimento do ensino de Ciências (KEANE, 2008). Assim, alguns temas são mais importantes para o ensino de Ciências em tais comunidades, como água, tempo, identidade, cultura e natureza, posto que abrangem diferentes visões de mundo (KEANE, 2008), além de se considerar que nesses grupos existem vínculos inseparáveis entre educação, socialização, sociabilidade, identidade, cultura, terra, território, espaço e comunidade (ARROYO, 2007).

Portanto, a abordagem do contexto local em tais escolas pode ser realizada por meio das relações dos indivíduos com a natureza, uma vez que se deve priorizar tais aspectos ao refletir que os camponeses interagem diretamente com a natureza, não a separando das relações sociais (CARDOSO; ARAÚJO, 2012a), realidade que difere dos ambientes urbanizados. Destarte, este artigo tem como objetivo relacionar as necessidades do ensino de Ciências na escola do campo com as abordagens dos aspectos sociais, econômicos, políticos e culturais propostas pelos Estudos Culturais e dos 
diversos saberes produzidos pelos diferentes grupos sociais. Para tanto, busca-se embasamento nas perspectivas multicultural e pluralista epistemológica das Ciências para a discussão da relação dos alunos com o ambiente natural em que vivem, por considerar os vínculos entre a comunidade e o território inseparáveis.

As discussões foram embasadas em contribuições dos Estudos Culturais para a educação (COSTA et alli, 2003; PARAÍSO, 2004; SILVA, 1995; 2007), no multiculturalismo (STANLEY ; BRICKHOUSE, 1994; TAN, 2011) e no pluralismo epistemológico no ensino de Ciências (COBERN; LOVING, 2001; BAPTISTA, 2010;).

\section{O ensino de Ciências na educação do campo}

A perspectiva da educação do campo exige uma contextualização dos temas trabalhados, pois necessita fazer o diálogo entre a teoria pedagógica e a realidade particular dos camponeses (CALDART, 2004). No entanto, o aspecto da adaptação dos conteúdos coloca a educação do campo em segundo plano (ARROYO, 2007), pois, na maioria dos casos, os currículos não são elaborados especialmente para esse público, predominando uma visão urbana de vida e desenvolvimento (ARROYO, 2007; SILVA et alli 2006). Com isso, os alunos não se sentem representados, diminuindo-lhes a autoestima (SILVA et alli, 2006). Por conseguinte, a vinculação com a realidade do meio é necessária, uma vez que a escola do campo possui uma identidade e temporalidade próprias (BRASIL, 2002). Assim, os educadores devem procurar conhecer os costumes, as experiências e os conhecimentos do aluno, assim como de sua família e comunidade, para que tais conhecimentos sejam valorizados e inseridos nos currículos escolares (BRASIL, 2002).

Dessa maneira, é possível observar que para escolas que atuam em comunidades rurais é importante que haja uma interação com a comunidade e com o ambiente que as cerca, contextualizando os conteúdos com fatores sociais, políticos, econômicos, culturais e ambientais que envolvem os grupos de pessoas que ali vivem.

Assim como nas outras disciplinas, o ensino de Ciências em escolas do campo necessita da contextualização de seus conteúdos, uma vez que a escola estabelece a tradução desses conhecimentos produzidos pelas pesquisas científicas para o público em geral (CARDOSO; ARAÚJO, 2012a), e que o conhecimento científico é bastante importante para a construção da representação social de ambiente natural (REIGOTA, 1999).

Sendo assim, o ensino de Ciências deve considerar quais conteúdos científicos são mais importantes na busca de soluções de problemáticas da comunidade local, bem como ter o cuidado de valorizar as práticas de tradição dos camponeses, auxiliando na compreensão do ambiente, emancipando os alunos (CARDOSO; ARAÚJO, 2012a).

No entanto, é necessário que os educadores considerem o ensino de Ciências nessas comunidades, respeitando a cultura e a identidade dos povos do campo, como a percepção do tempo, os ciclos da natureza, os valores da terra e do trabalho, as festas populares, a religiosidade, a história e os valores da comunidade, entre outros fatores (BRANDÃO, 2006).

Para tanto, é necessário que a formação inicial dos docentes contemple a importância do saber multicultural das salas de aula. Nesse sentido, Arroyo (2007), ao sugerir políticas de formação de educadores do campo, destaca que o aspecto fundamental para a formação desses professores seria o entendimento de que o território, o lugar e a terra são matrizes formadoras capazes de tornar a escola um local de formação, de modo que é necessário que as escolas camponesas construam um currículo fundamentado nas questões da comunidade e da cultura local, adotando assim uma política pedagógica apropriada (CARDOSO; ARAÚJO, 2012a).

Diante disto, faz-se necessária a inclusão da temática das especificidades da educação do campo nos cursos de formação inicial das licenciaturas, bem como promover cursos de formação continuada ao corpo docente que já atua nessas áreas. Desse modo, torna-se possível uma formação docente sensível aos diferentes saberes e modos de vida dos povos do campo. 
Formar o professor na perspectiva multicultural implica a construção de identidades docentes sensíveis à diversidade cultural, pois permite compreender o conhecimento e o currículo como processos discursivos, marcados por relações de poder e que participam na formação de identidades com base em conteúdos preestabelecidos e pretensões de verdades únicas (CANEN; XAVIER, 2005).

Dessa forma, para as autoras, os docentes multiculturais devem ser aptos a formular alternativas discursivas transformadoras e desafiadoras de identidades e de estereótipos. Nesse sentido, professores de Ciências e Biologia multiculturais preocupam-se em trabalhar os diversos saberes juntamente com o conhecimento científico em sala de aula, de modo a promover o enriquecimento da visão de mundo de seus alunos. Diante dessas necessidades, proponho neste artigo a utilização de contribuições dos Estudos Culturais para a educação, visando à abordagem e discussão de aspectos sociais, econômicos, políticos e culturais inscritos nos currículos de escolas localizadas em ambientes não urbanizados.

\section{As contribuições dos Estudos Culturais para a educação do campo}

Os Estudos Culturais são um campo que estuda os vários aspectos da cultura na sociedade, com origem na Inglaterra após a fundação do Centro de Estudos Culturais Contemporâneos, que tinha por objetivo discutir aspectos relacionados à cultura em geral (PARAísO, 2004). Os Estudos Culturais não se definem como uma disciplina, mas sim como uma intersecção de várias disciplinas no estudo da influência da cultura na sociedade, de forma que aproveitam os conhecimentos dos campos que forem necessários para produzir o conhecimento exigido na construção do estudo que está sendo desenvolvido (NELSON et alli, 1995; ESCOSTEGUY, 2010).

Nesta perspectiva, considera-se que todas as práticas sociais podem ser analisadas por meio da cultura, pois esta corresponde ao lado subjetivo das relações sociais (JOHNSON, 2010). Assim, os Estudos Culturais enfatizam o papel constitutivo da cultura em todos os aspectos da vida social, o que ressalta o significado político da cultura, pois é por meio dela que os significados dos grupos subordinados procuram combater os significados impostos pelos grupos mais poderosos na sociedade (COSTA et alli, 2003).

Assim, esse campo de estudos traz para a educação, principalmente para as discussões sobre currículo, conceitos que fornecem novos olhares às práticas pedagógicas, pois "mostram como as lutas por imposições de significados ocorrem em diferentes espaços e por meio de diferentes artefatos" (PARAísO, 2004, pg. 54), haja vista que a escola e o currículo estão no centro da produção social, já que o conhecimento possui estreita relação com conceitos de poder e identidade social (SILVA, 1995).

Logo, o currículo envolve-se na produção de sujeitos, elaborando formas de melhor organizar as experiências do conhecimento e de produzir esses sujeitos (COSTA et alli, 2003). Para os autores, o currículo escolar é um campo no qual diversos grupos tentam estabelecer sua hegemonia, pois seus saberes e práticas produzem tipos particulares de sujeitos e identidades.

Dessa forma, para compreender os conceitos de cultura, identidade e diferença é necessário entender as representações, os significados e os sistemas simbólicos. A representação inclui práticas de significação e os sistemas simbólicos pelos quais os significados são construídos ao considerar que cada cultura tem suas próprias formas de classificar o mundo, formando um sistema classificatório a fim de manter alguma ordem social (SILVA, 2007).

Ainda segundo o autor, por intermédio desse sistema, institui-se um princípio de diferença em uma população, o que causa a divisão dela em pelo menos dois grupos, formando identidades, a começar da relação que existe entre eles e a marcação das diferenças existentes, em uma relação de dependência entre identidade e diferença.

Diante do exposto, entender a cultura como prática de significação é vê-la intrinsecamente relacionada às relações de poder na sociedade, pois a identidade e a diferença são produzidas nas relações culturais e sociais, sendo assim sujeitas às relações de poder (GUIMARÃES, 2007). Essas 
práticas de significação não são inocentes, visto que a enunciação da identidade e a marcação da diferença traduzem os desejos de um grupo de alcançar bens sociais, pois, ao afirmar a identidade, o sujeito afirma o que ele não é, em um ato de inclusão e exclusão (SILVA, 2007).

Assim, a identidade e a diferença estão ligadas aos sistemas de representação, que são uma forma de atribuir sentido às coisas. É por meio da representação que construímos a identidade do outro e a nossa (PARAÍSO, 2004), pois quem tem o poder de representar, de atribuir significados, tem o poder de definir e determinar a identidade a ser seguida por determinado grupo, seja ele uma comunidade ou uma nação, evidenciando a estreita ligação com as relações de poder (SILVA, 2007).

De fato, as disputas de poder entre as culturas fazem com que algumas delas se sobreponham em relação a outras (PARAÍSO, 2004). A globalização contribui para tal fato, já que a homogeneidade da cultura promovida pelo mercado global leva a um distanciamento da cultura local e da comunidade (SILVA, 2007). Entretanto, os Estudos Culturais oferecem espaços alternativos de atuação visando ao confronto da concepção de distinção hierárquica entre culturas, como entre os conceitos de "alta cultura ou cultura erudita" e "cultura de massa ou cultura popular" (COSTA et alli, 2003).

Trazendo essas discussões para o contexto da escola, a prática pedagógica deve possibilitar aos alunos o desenvolvimento de um senso crítico e o questionamento a esse sistema de dominação da representação (SILVA, 2007). Os currículos inspirados em uma perspectiva culturalista devem contemplar atividades e materiais que permitam desenvolver no estudante o questionamento das culturas hegemônicas (PARAÍsO, 2004).

A escola, por meio do currículo, promove a legitimação da cultura das classes dominantes, pois assim como qualquer outro artefato cultural, o currículo nos constrói como sujeito (SILVA, 1995). Por intermédio da organização do currículo é possível observar qual tipo de conhecimento é legítimo ou não; refletir sobre a organização da sociedade; observar quais grupos sociais podem ser representados e quais não são. Essa seleção de conhecimentos e sua classificação, promovidas pelo currículo, inscreve o poder dentro de si, pois fixam noções de gênero, raça e classe (SILVA, 1995).

Entretanto, existem formas de ensinar os alunos a identificarem essas relações de poder no interior do currículo por intermédio de uma educação fundamentalmente política, na qual o ponto central seria aprender a questionar as representações atuais por meio de perguntas sobre as representações que foram construídas no conhecimento que compõe o currículo (SILVA, 1995; 2007). Assim, considerando que as representações não são fixas e estáveis, o currículo será um campo de luta pela representação, desconstruindo as identidades hegemônicas (SILVA, 2007).

Dentre as perspectivas de se trabalhar um currículo culturalista e que englobe as necessidades da educação do campo e as questões trazidas pelos Estudos Culturais, temos a educação baseada no conceito de lugar (place-based education. O conceito de lugar é problematizado nas suas diversas perspectivas e modos de saber, consideram-no-o como um conceito construído com base em noções de espaço, tempo, cultura e construções históricas, construído e reconstruído simultaneamente por meio das interações humanas (COUGHLIN; KIRCH, 2010). Com isso, desenvolve-se um senso de pertencimento ao local, visto que se entende que o território, o lugar e a terra são elementos fundamentais para a identidade de comunidades camponesas (ARROYO, 2011).

A presente perspectiva propõe explicitar em sala de aula as ideologias e os aspectos que compõem o conhecimento do mundo, uma vez que esses conhecimentos estão relacionados ao contexto histórico e cultural de certo local numa determinada época, e não se pode compreender tal conhecimento sem considerar os contextos (COUGHLIN; KIRCH, 2010):

Um dado recorte espacial é sustentado, explicado, justificado, legitimado por dadas formas de saber, que se materializam em ações e discursos, práticas discursivas e não discursivas. A região é, em grande medida, fruto dos saberes, dos discursos que a constituíram e que a sustentam (ALBUQUERQUE-JUNIOR, 2011).

Assim, o senso de lugar (sense of place) dos alunos deriva de diversas dimensões das suas ex- 
periências de vida (geográficas, biológicas, históricas, socioculturais e políticas) e é entendido como uma relação entre uma pessoa e um lugar; abrange como os alunos vivem e quais relações eles têm com o ambiente; e ajuda-os a conectar suas experiências com a ciência ensinada na escola (KINCHELOE et al, 2006). Essa perspectiva é interessante quando se objetiva um ensino de Ciências que forme cidadãos atuantes em suas comunidades.

Dessa forma, em relação ao ensino de Ciências, é preciso entender que os alunos querem aprender uma ciência que seja significativa na sua realidade, composta de saberes que atendam às perspectivas de sua comunidade (AINKHEAD et alli, 2006). Para tanto, ao ensinar Ciências em comunidades tradicionais, é necessário compreender a ciência e as diferentes formas de relacionamento com o mundo natural das diversas culturas, portanto, a forma de aprender Ciências está profundamente relacionada ao lugar e fundamentada na cultura, em valores e tradições (AINKHEAD et alli, 2006).

Para ensinar Ciências sob a perspectiva de lugar, é preciso ir além da abordagem de tópicos de conhecimento local (por exemplo, plantas nativas) e da discussão dos conceitos envolvidos, abordando a forma como os conhecimentos são construídos nas relações e atividades que os sujeitos mantêm com o mundo natural em uma perspectiva epistemológica (AINKHEAD et alli, 2006).

Nesse sentido, é fundamental conhecer as discussões que explicam epistemologicamente a relação entre o saberes científicos e tradicionais e como estes podem se relacionar a fim de embasar a compreensão do mundo natural pelos alunos e a relação deles com o ambiente.

\section{As formas de compreender o mundo natural e o ensino de Ciências}

Trazendo as discussões de uma educação política e multicultural para o ensino de Ciências, é possível observar como elas podem contribuir para a construção de uma visão global de mundo, a qual é construída por meio da articulação de conhecimentos científicos e saberes populares. O diálogo promovido entre o saber de tradição e o saber científico viabiliza a construção do saber escolar do campo (CARDOSO; ARAÚJO, 2012a) necessário a uma escola comprometida com a formação de cidadãos atuantes em sua comunidade.

No entanto, segundo pesquisadores da linha multiculturalista no ensino de Ciências, ainda é possível observar um caráter essencialmente universalista no ensino dessa disciplina, ou seja, a ciência ensinada na escola consiste em uma forma de pensar neutra, inocente, sem implicações sociais e políticas, que visa somente obter conhecimentos sobre o mundo natural (STANLEY; BRICKHOUSE, 1994; TAN, 2011). Entretanto, sabe-se que não se tem uma ciência livre de relações políticas, econômicas e éticas com a sociedade (LOPES, 1999; EL-HANI; SEPULVEDA, 2007).

Na visão dos multiculturalistas Stanley e Brickhouse (1994), o universalismo defende que a interpretação do mundo natural não é relacionada à cultura, ao gênero, à raça, à etnia ou à orientação sexual do aluno. Para fundamentar suas afirmações, esses autores listam algumas críticas a alguns princípios universalistas de produzir conhecimento científico: o fato de acreditar que a realidade pode ser dividida em segmentos para serem estudados independentemente; a crença na existência de linguagem científica e métodos de estudo universais; a questão de que os conhecimentos podem e devem ser verificados e justificados por teorias e experimentos; o fato de que teoria e observação, assim como o observador e o observado, podem ser separados com base em um método livre de valores e a separação dos fatos e significados; e a independência temporal e contextual das observações (STANLEY ; BRICKHOUSE, 1994).

Desse modo, para alguns autores, a visão universalista no ensino de Ciências promove a instrução científica, a qual tende a forçar o aluno a abandonar sua visão de mundo, de forma que haja o abandono desses novos conhecimentos após a avaliação dos conteúdos ministrados na disciplina, pois não condizem com a realidade do estudante (BAPTISTA, 2010).

Alguns autores defendem o multiculturalismo nas ciências e destacam o fato de que o conhecimento científico só é validado após a avaliação de uma comunidade de cientistas, ou seja, o que é 
estudado e os métodos escolhidos são determinados com base no do diálogo e na interpretação humana (STANLEY; BRICKHOUSE, 1994; TAN, 2011). Dessa forma, ao reconhecer que o conhecimento científico e suas práticas são normas estabelecidas e compartilhadas em comunidades durante um determinado período de tempo, percebe-se que a Ciência - assim como o ensino de Ciências - é um empreendimento cultural (TAN, 2011).

Ao considerar tais fatores, os multiculturalistas desejam, assim, que sejam consideradas as várias visões de mundo para entender e determinar um conhecimento (STANLEY; BRICKHOUSE, 1994), uma vez que a ciência é uma postura relativa à forma de organizar o pensamento e a ação diante do que é desconhecido (BIZZO, 2009), caracterizando-a como uma forma cultural de conhecimento (TAN, 2011).

Já autores da linha universalista no ensino de Ciências, a exemplo de Siegel (2002), no texto Multiculturalism, universalism and science education: in search of common ground, rebatem as críticas ao universalismo feitas por Stanley e Brickhouse (1994), afirmando que em muitos pontos não há divergência de ideias entre as duas correntes de pensamento, inclusive concordando com a existência de influência da cultura na ciência. Siegel esclarece que os conhecimentos tradicionais podem contribuir para o conhecimento científico, uma vez que muitas vezes são baseados na observação do mundo natural.

No entanto, o conhecimento ocidental é considerado superior às outras formas de pensamento porque proporciona um conhecimento profundo sobre o mundo natural por intermédio de teorias explanatórias e testáveis. Assim, ele concorda que os outros sistemas de pensamento devem estar presentes nas discussões em sala de aula, mas que é necessário deixar claro aos alunos a superioridade da ciência ocidental (SIEGEL, 2002).

No ensino de Ciências, Stanley e Brickhouse (1994) não defendem que as ciências das várias culturas tenham o mesmo espaço que a ciência ocidental, mas sim que, por meio de alguns exemplos, seja esclarecido aos alunos que a ciência ocidental é somente uma dentre as várias formas de se pensar.

Outra sugestão dos autores é que seja contada a história da ciência ocidental, objetivando revelar como têm ocorrido as mudanças nas teorias e metodologias ao longo do tempo, o que é necessário para incentivar o pensamento crítico sobre a que propósitos tem servido a ciência ocidental, e como estes poderiam ser alterados para a criação de ciências futuras que melhor atendam às necessidades das sociedades diversas que lhes dão suporte (STANLEY; BRICKHOUSE, 1994).

Considerando que as salas de aula congregam diferentes visões de mundo, as quais são influenciadas pelas culturas que ali convivem, (BAPTISTA, 2010), a corrente de pensamento dos pluralistas epistemológicos (COBERN; LOVING, 2001; BAPTISTA, 2007; 2010; EL-HANI; SEPULVEDA, 2007; TRÉZ, 2011) também defende a inserção dos diferentes saberes no ensino de Ciências. No entanto, nessa concepção pluralista, esses saberes não podem ser classificados como ciência, uma vez que tal nomenclatura caracteriza a forma de pensamento da sociedade ocidental.

Desse modo, os autores propõem um diálogo entre os diferentes saberes em sala de aula, permitindo que o aluno tenha o discernimento para escolher qual tipo de saber é mais pertinente para cada situação (LOPES, 1999; EL-HANI; SEPULVEDA, 2007). Portanto, o ensino de Ciências que considera o pluralismo epistemológico auxilia na negociação e transposição de fronteiras culturais para que o ensino possibilite a aprendizagem de teorias e conceitos científicos, mesmo quando forem conflitantes com a visão de mundo dos alunos (EL-HANI; SEPULVEDA, 2007).

Por visão de mundo compreende-se a organização da mente do indivíduo, composta por pressupostos ou suposições que influenciam as pessoas a pensarem, sentirem e agirem em padrões previsíveis em relação ao mundo exterior, uma vez que embasa o raciocínio, ou seja, explica ou justifica o pensamento ou ato (COBERN, 2000). Para o autor, essas ideias determinam o que as pessoas são bem como o que não são, influenciando as relações com as outras pessoas e com o ambiente. Assim, o autor conclui que a visão de mundo compreende vários saberes congregados que subsidiam ideias, conceitos e ações dos indivíduos, a depender do contexto em que se encontram. 
Sob o raciocínio de que as pessoas utilizam diversos modos de pensar a depender do domínio em que se encontram, Mortimer (1996) defende o modelo de mudança de perfis conceituais. Nesse modelo, as concepções alternativas dos alunos não são eliminadas no processo de ensino científico, elas sempre estão presentes de forma residual no aluno, de forma que ele mantenha a velha concepção enquanto, gradualmente, incorpora elementos de uma nova concepção (MORTIMER, 1996).

Portanto, a visão de mundo ajuda a manter a ordem e o equilíbrio mental por meio da interação dialética entre os pressupostos existentes e as mudanças ambientais (COBERN, 2000). Assim, entende-se que o perfil conceitual do indivíduo permite diferentes formas de pensar, e que, mesmo sendo contraditórias, convivem de modo estável na ecologia conceitual de uma única pessoa, uma vez que é possível utilizar diferentes modos de pensar em diversos domínios, já que uma nova concepção não necessariamente substitui ideias prévias e alternativas. Ou seja, os significados "aceitos" e "não aceitos" são conscientemente diferenciados e aplicados devidamente de acordo com a situação (MORTIMER, 1996).

É importante destacar que o pluralismo epistemológico procura mostrar aos alunos que a ciência pode se valer de outros domínios de saberes, como também que ela pode fazer o que os outros domínios de saberes não podem (COBERN; LOVING, 2001). Não deve haver a tentativa de fazer com que os estudantes abandonem seus conhecimentos com o objetivo de ter a ciência como única fonte de conhecimentos válidos, mas sim fazer com que tenham a oportunidade de reconhecer os domínios particulares de cada saber (BAPTISTA, 2010).

Logo, a demarcação de saberes é promovida pelo diálogo, que mostra como as visões tradicionais são diferentes da científica. Essa prática pode ser realizada por meio da argumentação, posto que o debate em sala de aula desenvolve nos alunos a consciência crítica, a autonomia, a emancipação e a valorização das culturas (COBERN; LOVING, 2001; BAPTISTA, 2010; TAN, 2011).

Dentre as várias possibilidades de realizar um ensino de Ciências pluralista, alguns autores sugerem a utilização dos saberes etnobiológicos para promover esse diálogo (BAPTISTA, 2007; TRÉZ, 2011). As etnociências investigam o conhecimento das populações humanas sobre os processos naturais (DIEGUES, 2001), e dentre elas está a etnobiologia, que estuda a relação entre a natureza e o sistema de crenças do homem nos vários ambientes (POSEY, 1987). Segundo o autor, a etnobiologia pode fornecer dados para a construção de uma política ecológica socialmente responsável, já que considera os conhecimentos científicos e populares e, assim, estabelece uma compreensão mútua dos interesses envolvidos.

Desse modo, a seleção de etnoconhecimentos para serem inseridos no ensino de Biologia, sendo respeitado o contexto do saber, faz um contraponto com a visão científica, contribuindo para ampliar a visão de mundo dos estudantes (TRÉZ, 2011). A seleção de conteúdos deve ser realizada, pois a proposta não visa somente à introdução de determinadas práticas e conteúdos, como também não procura abranger um universo vasto de saberes. $O$ professor, selecionando alguns saberes pertinentes situados no conteúdo que está sendo ministrado e respeitando os respectivos contextos de cada saber, já contrapõe o unicismo da visão científica e contribui para a ampliação de possibilidades que contornam os saberes em relação à biologia. Somado a isso, ao pensarmos em educação ambiental, estudos têm mostrado que alguns valores de outras culturas apresentam conhecimentos que são fruto da relação direta das pessoas com a natureza que são bastante eficazes na sua preservação (EL-HANI; SEPULVEDA, 2007).

Para os autores, esses conhecimentos, denominados "conhecimento ecológico tradicional" (expressão internacionalmente conhecida como TEK - Traditional Ecological Knowledge), são passados de geração em geração e podem contribuir para a construção de soluções para a crise ambiental. Logo, é necessário conhecer melhor a visão de conservação das populações tradicionais para ser parte de uma nova política de conservação ambiental (DIEGUES, 2001).

Contudo, o ensino de Ciências geralmente mostra dois enfoques: um que aborda o domínio de conceitos e informações sem maiores significados, e outro que alia a competência técnica a um compromisso político de superação dos problemas ambientais atuais, sendo necessário aliar a 
dimensão técnica (no sentido de conceitos e informações) à dimensão política, já que, para que a escola cumpra sua função educativa efetivamente, esses dois aspectos são indispensáveis (CUNHA, 2006).

Isso se deve ao fato de que o saber ambiental deve surgir da problematização dos conhecimentos científicos por meio do seu entrelaçamento com conhecimentos não científicos, o que ocasiona a construção de uma nova racionalidade teórica, social e produtiva que inclui novas teorias e instrumentos para reorientar o manejo produtivo da natureza, sustentada por valores (qualidade de vida, identidades culturais, sentidos da existência) que não aspiram a ser considerados como ciência (LEFF, 1998, p. 231).

Sendo assim, ninguém está livre dos efeitos de condicionamentos anteriores que são impostos por suas próprias representações, linguagem ou cultura, posto que pensamos por meio de uma linguagem e organizamos as ideias de acordo com os sistemas condicionados por nossas representações e cultura (MOSCOVICl, 2003). O saber ambiental não é algo dado aos alunos, mas sim construído por suas "significações primárias", considerando que é inserido em um meio ideológico e social (LEFF, 1998), e baseado nas representações das pessoas sobre seu meio (DIEGUES, 2001; REIGOTA, 1999; 2004).

A forma como as pessoas veem e se relacionam com a natureza são constituídas culturalmente, pois por intermédio dos artefatos culturais (vídeos, revistas, livros didáticos, televisão, entre outros) são dados significados à natureza, como também nos relacionamos com ela, de modo que devemos assumir uma posição em relação ao meio ambiente, sendo que não é, necessariamente, a intenção explícita dos artefatos que expressam a relação homem-ambiente (GUIMARÃES, 2007).

Diante dessas discussões, é importante investigar como o relacionamento com o ambiente local é construído por intermédio das práticas cotidianas e pelo ensino de Ciências nas comunidades do campo, pois tais saberes compõem os significados que os alunos atribuem ao ambiente, discutindo identidade, cotidiano e conteúdos científicos.

\section{Considerações finais}

Com este artigo buscamos relacionar as necessidades do ensino de Ciências na escola do campo com a abordagem dos aspectos sociais, econômicos, políticos e culturais propostas pelos Estudos Culturais e pelos diversos saberes produzidos por diferentes grupos sociais que formam os povos do campo. Para um melhor embasamento de nossa discussão, ao se pensar especificamente sobre o ensino de Ciências, trouxemos as contribuições das visões multicultural e pluralista epistemológica do ensino de Ciências, no sentido de valorizar as relações dos alunos com o ambiente natural em que a comunidade está inserida durante as aulas de Ciências.

Para tanto, sugerimos a inserção de conhecimentos etnobiológicos nos currículos de Ciências de escolas do campo, contribuindo para ampliação dos saberes em relação às Ciências e à Biologia, como também contrapondo o unicismo da visão científica e valorizando o conhecimento cultural da comunidade acerca de temas como biodiversidade e conservação, promovendo a identificação dos alunos com a ciência escolar.

Assim, este trabalho defende uma postura pluralista epistemológica do ensino de Ciências na educação do campo, pois acredita-se que os alunos podem conviver com os diversos saberes, aplicando-os na situação adequada. Adotar uma postura pluralista epistemológica no ensino de Ciências em escolas do campo é uma forma de atender aos pressupostos da Educação do Campo, assim como as recomendações dos Estudos Culturais para a educação, o que proporciona a discussão e o respeito a aspectos como a identidade e a cultura dos alunos.

\section{Referências}

AGÊNCIA BRASIL, Luiz Inácio Lula da Silva, Escola no campo espera política de educação própria e extensão 
universitária, disponível em: http://agenciabrasil.ebc.com.br/noticia/2010-08-06/escola-no-campo-esperapolitica-de-educacao-propria-e-extensao-universitaria. Acesso em 12 jul. 2011.

AINKHEAD, G.; CALABRESE, A.B; CHINN, P.W.U. Toward A Politics Of Place-Based Science Education. Cultural Studies of Science Education, v.1, P. 403-416. 2006. cross $^{\text {ref }}$ http://dx.doi.org/10.1007/s11422-006-9015-z

ALBUQUERQUE-JUNIOR, D.M. O objeto em fuga: algumas reflexões em torno do conceito de região. Disponível em: <http://www.cchla.ufrn.br/ppgh/docentes/durval/artigos/objeto em fuga.pdf. 2011>. Acessado em: 02 set 2012.

ARROYO, M. G. Políticas de formação de educadores(as) do campo. Cad. Cedes, Campinas, v.27 n.72, 2007. p. 157-176.

. Currículo, território em disputa. Petrópolis: Vozes, 2011. 374 p.

BAPTISTA, G. C. S. A contribuição da etnobiologia para o ensino e a aprendizagem de Ciências: estudo de caso em uma escola pública da Bahia. 2007. 188 f. Dissertação (Mestrado em Educação Científica) - Universidade Federal da Bahia, Salvador.

. Importância da demarcação de saberes no ensino de Ciências para sociedades tradicionais. Ciência \& Educação, v.16, n.3, 2010, p. 679-694. cross ${ }^{\text {ref }}$ http://dx.doi.org/10.1590/S1516-73132010000300012

BIZZO, N. Ciências: fácil ou difícil? São Paulo: Biruta, 2009. 159 p.

BRANDÃO, E. Educação do campo: pedagogia da sobrevivência. IN: BRANDÃO, E. ; CECILIO, M. A. Educação: campo e cidade - territórios do saber. Maringá: Massoni, 2006.

BRASIL. Diretrizes Operacionais para a educação básica nas escolas do campo. Brasília, 2002.

CALDART, R.S. Elementos para a construção do projeto político e pedagógico da educação no campo. IN: MOLINA, M.C. ; JESUS, S.M.S.A. (Org.). Contribuições para a construção de um projeto de educação do campo. Brasília: Articulação Nacional "Por uma educação do campo", 2004.

CANEN, A.; XAVIER, G.P.M. Multiculturalismo, pesquisa e formação de professores: o caso das Diretrizes Curriculares para a formação docente. Ensaio: aval. pol. públ. Educ., v.13, n.48, p. 333-344, 2005.

CARDOSO, L. R.; ARAÚJO, M.I.O. Currículo e Ciências: professores e escolas do campo. Revista Ensaio, v.14, n.2, p. 121-135. 2012a. cross $^{\text {ref }}$ http://dx.doi.org/10.1590/1983-21172013140208

COBERN, W. Everyday thoughts about nature. Dordrecht: Kluwer, 2000. cross ${ }^{\text {ref }}$ http://dx.doi.org/10.1007/978$\underline{94-011-4171-0}$

COBERN, W.; LOVING, C. C. Defining 'Science" in a multicultural world: implications for science education. Science Education, v.85, 2001. 50-67. cross $^{\text {ref }}$ http://dx.doi.org/10.1002/1098-237X(200101)85:1<50::AID$\underline{\mathrm{SCE} 5>3.0 . \mathrm{CO} ; 2-\mathrm{G}}$

COSTA, M. V.; SILVEIRA, R. H.; SOMMER, L. H. Estudos culturais, educação e pedagogia. Revista Brasileira de Educação, v.23, 2003.

COUGHLIN, C.A.; KIRCH, S. A. Place-based education: a transformative activist stance. Cultural Studies of Science Education, v.5, P.911-921. 2010. cross $^{\text {ref }}$ http://dx.doi.org/10.1007/s11422-010-9290-6

CUNHA, M. M. S. Apropriações didático-pedagógicas da temática ambiental no ensino de Ciências. IN: CUNHA, M. M. S. Questões atuais em educação. João Pessoa: Editora universitária/UFPB, 2006. 86 p.

DIEGUES, A. C. S. O mito moderno da natureza intocada. 3ed. São Paulo: Hucitec, 2001. 169 p. 
EL-HANI, C., N., SEPÚLVEDA, C. Referenciais teóricos e subsídios metodológicos para a pesquisa sobre as relações entre educação científica e cultura. In: SANTOS, F. M. T. dos, GRECA, I. M. (Orgs.). A pesquisa em Ensino de Ciências no Brasil e suas metodologias. Ijuí: Unijuí, 2007.

ESCOSTEGUY, A.C. Estudos culturais: uma introdução. IN: SILVA, T. T. O que é, afinal, estudos culturais? Belo Horizonte: Autentica, 2010. 240 p.

GUIMARÃES, L.B. Pesquisa em Educação Ambiental: olhares atentos à cultura. IN: WORTMANN, M.L.C; SANTOS, L.H.S; RIPOLI, D; SOUZA, N.G.S. ; KINDEL, E.A.I. Ensaios em Estudos Culturais, Educação e Ciência. 1 ed. Porto Alegre: UFRGS, 2007. P. 237-246.

JOHSON, R. O que é, afinal, estudos culturais? IN: SILVA, T.T. O que é, afinal, estudos culturais? Belo Horizonte: Autentica, 2010. 240 p.

KEANE, M. Science education and worldview. Cult Stud of Sci Educ, 3. p.587-621. 2008. cross $^{\text {ref }} \underline{\text { http://dx.doi. }}$ org/10.1007/s11422-007-9086-5

KINCHELOE, J.L.; MCKINLEY, E.; LIM, M., BARTON, A.C. Conversation On 'Sense Of Place' In Science Learning. Cultural Studies of Science Education, v.1, p. 143-160. 2006. cross ${ }^{\text {ref }}$ http://dx.doi.org/10.1007/s11422-0059003-8

LEFF, E. Saber ambiental: sustentabilidade, racionalidade, complexidade, poder. Petrópolis: Vozes, 1998. 494 p.

LOPES, A. R. C. Conhecimento científico. In: Conhecimento escolar: ciência e cotidiano. Rio de Janeiro : EdUERJ, 1999. p. 126- 136.

MORTIMER, E.F. Construtivismo, Mudança conceitual e ensino de Ciências: para onde vamos? Investigações em Ensino de Ciências - V.1, n.1, pp.20-39, 1996.

MOSCOVICI, S. Representações sociais: investigações em psicologia social. Petrópolis: Vozes, 2003. 404 p.

NELSON, C; TREICHLER, P. A.; GROSSBERG, L. Estudos culturais: uma introdução. IN: Alienígenas na sala de aula: uma introdução aos estudos culturais em educação. Petrópolis, RJ: Vozes, 1995.

PARAÍSO, M. A. Contribuições dos Estudos Culturais para a Educação. Presença Pedagógica, v. 10, n. 55, 2004.

PETTY, M.; TOMBIM, A.; VERA, R. Uma alternativa de educação rural. In: WERTHEIN, J. ; BORDENAVE, J.D. [Org.]. Educação rural no terceiro mundo: experiências e novas alternativas. Rio de janeiro: Paz e terra, 1981.

POSEY, D. A. Etnobiologia: teoria e prática. IN: RIBEIRO, B. G. [Cord.]. Suma etnológica brasileira. Petrópolis: Vozes, 1987.

REIGOTA, M. A floresta e a escola: por uma Educação Ambiental pós-moderna. São Paulo: Cortez, 1999.

. Meio ambiente e representação social. 6 ed. São Paulo: Cortez, 2004.

SILVA, L.H.; MORAIS, T.C. ; BOF, A.M. A educação no meio rural do Brasil: revisão da literatura. IN: BOF, A.M. (Org.). A educação rural no Brasil. Brasília: Instituto Nacional de Estudos e Pesquisas Educacionais Anísio Teixeira, 2006.

SILVA, T. T. A produção social da identidade e da diferença. In: SILVA, T. T; HALL, S.; WOODWARD, K. Identidade e diferença: a perspectiva dos Estudos Culturais. Petrópolis, RJ: Vozes, 2007.

Currículo e Identidade social: Territórios contestados. IN: SILVA, T.T. Alienígenas na sala de aula: uma introdução aos estudos culturais em educação. . Petrópolis, RJ: Vozes, 1995. p. 190-207. 
SOARES, S.; RAZO, R.; FARIÑAS, M. Perfil estatístico da educação rural: Origem socioeconômica desfavorecida, insumos escolares deficientes e resultados inaceitáveis. IN: BOF, A.M. A educação no Brasil rural. Brasília: Instituto Nacional de Estudos e Pesquisas Educacionais Anísio Teixeira, 2006.

STANLEY, W. B.; BRICKHOUSE, N. W. Multiculturalism, Universalism and Science Education. Science Education, v. 78, n.4, 1994. P. 387-398. cross $^{\text {ref }}$ http://dx.doi.org/10.1002/sce.3730780405

SIEGEL, H. Multiculturalism, Universalism and Science Education: In search of common ground. Science Education, v.86, 2002. P. 803-820. cross $^{\text {ref }}$ http://dx.doi.org/10.1002/sce.1052

TAN, A. L. Home culture, science, school and science learning: is reconciliation possible? Cult. Stud of Sci Educ, v.6, p. 559-567. 2011. cross $^{\text {ref }}$ http://dx.doi.org/10.1007/s11422-011-9343-5

TRÉZ, T.A. Feyeraband, interculturalismo e etnobiologia: algumas possíveis articulações no ensino de biologia. Revista Biotemas, v.24, n.3, 2011.

Recebido em janeiro de 2015. Aprovado em 10 de outubro de 2015. 